\title{
Analisis Image Comments to Video Comments Ratio Instagram Pada 5 Tim Mobile Legend Bang Bang Terbaik di Indonesia Pada Tahun 2020
}

\author{
I Putu Gede Raditya Pratama \\ gederaditya233@gmail.com
}

\begin{abstract}
In this digital era, information and communication technology has made enormous progress, making it easier for people to interact through social media. One of the most widely used social media applications is Instagram. This study aims to find the ratios found on social media Instagram. These ratios can later be used to perform analyzes that can be measured mathematically. The research method used is exploratory to find the variables contained in Instagram. These variables will be juxtaposed to be tested for relevance so as to find the relevant ratio used to assess the performance of an Instagram account. The results of this Instagram social media research show that there are 14 ratios that can be used to assess, measure and compare the credibility of an Instagram account. The implication of the discovery of this ratio is that further researchers can conduct quantitative research in measuring, assessing and comparing accounts on Instagram.
\end{abstract}

Keywords: Social Media, Instagram, Instagram Ratio, Credibility of Social Media Accounts.

\begin{abstract}
ABSTRAK
Di era digital ini, teknologi informasi dan komunikasi sudah mengalami kemajuan yang sangat besar sehingga memudahakan orang dalam berinteraksi melalui media sosial. Salah satu aplikasi media sosial yang banyak digunakan adalah Instagram. Penelitian ini bertujuan untuk menemukan rasio - rasio yang terdapat pada sosial media Instagram. Rasio - rasio ini yang nantinya dapat digunakan untuk melakukan analisa yang dapat terukur secara matematis. Metode penelitian yang digunakan yaitu ekploratif untuk menemukan variabel - variabel yang terdapat pada Instagram. Variabel tersebut akan disandingkan untuk diuji relevansi nya sehingga menemukan rasio yang relevan digunakan menilai peforma sebuah akun Instagram yang. Hasil dari penelitian sosial media Instagram ini menunjukan bahwa terdapat 14 rasio yang dapat digunakan untuk menilai , mengukur serta membandingkan kredibilitas dari sebuah akun Instagram. Implikasi dari penemuan rasio ini adalah para peneliti selanjutnya dapat melakukan penelitian kuantitatif dalam mengukur, menilai serta membandingkan akun-akun yang terdapat pada instagram.
\end{abstract}

Kata Kunci : Media sosial, Instagram, Rasio Instagram, Kredibilitas Akun Sosial Media. 


\section{PENDAhUluAN}

Di era digital ini, teknologi informasi dan komunikasi sudah mengalami kemajuan yang sangat besar. Salah satu dapat dirasakan adalah cara berintekasi yang dimudahkan oleh teknologi dengan menggunakan media sosial. Dampak yang diberikan oleh media sosial sangat besar, khususnya dalam kehudpan sehari-hari, media sosial digunakan sebagai sarana berinteraksi dalam kegiatan keseharian di masyarakat. Selain secara tatap muka, komunikasi juga dapat dilaksanakan melalui beraneka ragam aplikasi media sosial di dunia maya. Layanan aplikasi media sosial dapat digunakan sebagai wadah berinteraksi untuk melakukan bisnis.

Cepatnya kemajuan teknologi khususnya media sosial, membuat para perusahan-perusahan berlomba-lomba dalam membuat kemajuan dalam membuat layanan aplikasi media sosial. Salah satu contoh aplikasi media sosial yang banyak digunakan adalah Instagram. Instagram adalah aplikasi medias sosial yang dibuat untuk membagikan foto dan video dari gawai pintar (Moreau, 2018).

Dengan adanya aplikasi Instagram sebagai media sosial, selain digunakan untuk berbagi informasi dan berinteraksi, instagram dapat digunakan sebagai personal branding melalui foto ataupun video yang di upload ke Instagram (Restusari \& Farida, 2019). Di Indonesia terdapat sebanyak 91,77 juta pengguna Instagram yang aktif (Inilah Negara Pengguna Instagram Terbanyak, Indonesia Urutan Berapa? | Databoks, n.d.). Besarnya pengguna Instagram yang aktif di Indonesia, itu merupakan peluang bagi organisasi atau tim, khususnya tim esport permainan mobile legend bang bang sebagai media marketing. Adapun 5 tim mobile legend bang bang terbaik di Indonesia pada tahun 2020, diantaranya yaitu : Onic Esport, Bigetron Esport, Alter Ego Esport, Evos Esport, RRQ (5 Tim Mobile Legends Terbaik Di Indonesia Musim Ini - Terminal Mojok, n.d.).

Metode yang digunakan dalam penelitian in adalah eksploratif kuantitatif yang akan menghitung rasio-rasio pada Instagram. Pada aplikasi media sosial Instagram terdapat 14 rasio yang relevan dan dapat digunakan sebagai media ukur kredibilitas akun yang akan di analisis (Hendika Permana, 2021). Pada penelitian ini berfokus pada menghitung kredibilitas image comments to video comments ratio 5 tim mobile legend bang bang terbaik di Indonesia pada tahun 2020, diantaranya yaitu : Onic Esport, Bigetron Esport, Alter Ego Esport, Evos Esport, RRQ (5 Tim Mobile Legends Terbaik Di Indonesia Musim Ini - Terminal Mojok, n.d.). penelitian ini bertujuan untuk mengetahui kredibilats performa dari akun Instagram 5 tim mobile legend bang bang terbaik di Indonesia pada tahun 2020 menggunakan image comments to video comments ratio.

\section{TINJAUAN PUSTAKA}

Kemajuan yang sangat besar pada bidang teknologi menyebabkan banyaknya perusahan yang berlomba-lomba dalam membuat aplikasi yang berguna bagi kehidupan khususnya aplikasi 
media sosial. Dimana aplikasi ini memiliki peminatnya di kalangangan masyarakat, contohnya : Instagram, Facebook, Twitter, TikTok, Whatsapp, dan lain-lainnya. Dari masa ke masa, penggunaan aplikasi sosial media membuat orang kecanduan, baik dari orang tua sampai anakanak, aktif dalam menggunakan aplikasi sosial media.

Instagram adalah jejaring sosial yang digunakan sebagi tempat menyebarkan dan berbagi informasi, berinteraksi dengan orang banyak, serta dapat mengenal lebih dekat dengan sesama pengguna Instagram melalui foto-foto, video yang diunggah (Febrina, 2019). Selain digunakan sebagai media berinteraksi, aplikasi Instagram juga digunakan untuk sosial media marketing. Instagram kini mulai banyak dilirik pebisnis online untuk memasarkan jasa dan produknya. Instagram memiliki fitur khusus untuk periklanan berupa Instagram Ads Sponsored.Fitur ini melibatkan Facebook dalam langkah pembuatannya, mengingat Instagram telah diakuisisi Facebook (Nur Arifah, 2015).

Di Indonesia sendiri, Instagram merupakan salah satu aplikasi yang paling banyak penggunanya. Dalam penggunaanya sering digunakan untuk membangun branding terhadap suatu produk ataupun orang. Hal ini dirasakan memiliki pengruh dalam dunia industri, sehingga menumbukan kualitas akun dalam menentukan tingkatan maupu kredibilitas suatu akun. Kredibilitas suatu akun Instagram adalah suatu hal yang sangat penting dalam segala aspek. Secara matematis, sebuah akun Instagram dapat diukur kredibilitas dari tingkat performa yang memerlukan skala pengukuran yang tertuang dalam rasio.

\section{METODE PENELITIAN}

Untuk mengetahui kredibilitas dari performa dari 5 akun Instagram 5 Tim 5 Tim Terbaik Mobile Legend di Indonesia Tahun 2020 pada penelitian ini menggunakan metode eksploratif kuantitatif. Metode menggunakan Penelitian tipe eksploratif, bertujuan memperdalam pengetahuan dan mencari ide-ide baru mengenai suatu gejala tertentu, menggambarkan fenomena sosial, dan menjelaskan bagaimana terjadinya suatu fenomena sosial untuk merumuskan masalah secara lebih terperinci atau mengembangkan hipotesis bukan menguji hipotesis (Mudjiyanto, 2018).

Penelitian ini bertujuan untuk mendapatkan nilai kredibilitas dari 5 akun Instagram 5 Tim 5 Tim Terbaik Mobile Legend di Indonesia Tahun 2020. Dalam penelitian ini memiliki beberapa tahap yang yang harus dilalui untuk mencari peringkat pertama akun Instagram tim mobile legend di Indonesia yang memiliki performa terbaik. Langkah-langkah yang dilakukan pada penelitian ini, diantaranya yaitu :

\section{Menentukan Objek yang Akan Dianalisa Dengan Melakukan Eksplorasi Pada Website.}

Eksplorasi dilakukan untuk mendapakan beberapa halaman website yang berisi informasi tentang objek yang hendak di teliti. Setelah menemukan informasi tentang nama-nama tim mobile legend di Indonesia yang akan diadikan objek penelitian. 
Langkah selanjutnya adalah mencari nama akun Instagram dari masing-masing tim mobile legend. Pastikan semua tim memiliki akun pada aplikasi sosial media Instagram.

\section{Menghitung Nilai Rata-Rata Variable Dari Top Vendor Smartphone di}

\section{Indonesia.}

Untuk mendapatkan nilai rata-rata, dilakukan penghitungan nilai variable image comments dan video comments. Variable adalah. Dengan cara mengambil minimal 10 postingan video dan 10 postingan image setelah itu, dihitung sehingga mendapatkan nilai rata-rata dari masing-masing variable.

\section{Menghitung Nilai Kredibilitas Rasio}

Pada tahap ini, peneliti menghitung nilai kredibilitas dari image comment to video comments dengan cara nilai variabel pertama dibagi nilai variabel kedua. Jika image comments memiliki nilai 300 dan video comments memiliki nilai 100, maka cara menghitungnya adalah $300: 100=3$. Sehingga nilai dari image comment to video comments yaitu 3 .

\section{Menentukan Peringkat Pada Akun Instagram}

Pada tahap terakhir yang dilakukan adalah menentukan perikat untuk setiap rasio yang ada. dalam penentuan peringkat diperlukan melihat karakteristik dari rasio yang di teliti. Jika rasio memiliki karakteristik yang tinggi maka objek yang mendapatkan nilai tertinggi mendapatkan rangking terendah dan objek yang mendapatkan hasil rendah mendapatkan rangking tertinggi. Untuk rasio memiliki karakteristik yang rendah maka objek yang mendapatkan nilai tertinggi mendapatkan rangking tertinggi dan objek yang mendapatkan hasil rendah mendapatkan rangking terendahi.

\section{HASIL \& PEMBAHASAN}

Akun Instagram dari 5 Tim Terbaik Mobile Legend di Indonesia Tahun 2020

1. Onic

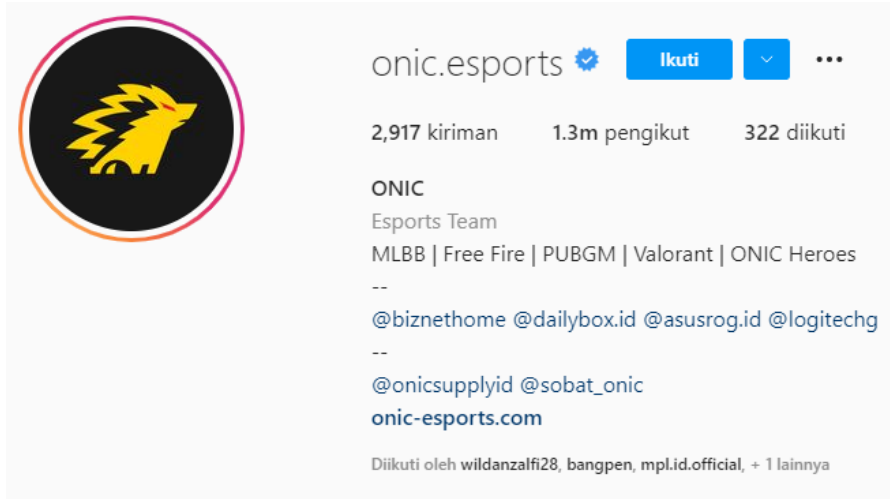

gambar 1. akun instagram onic esports

Sumber : https://www.instagram.com/onic.esports/?hl=id (akses pada 22-10-2021) 


\section{Bigetron}

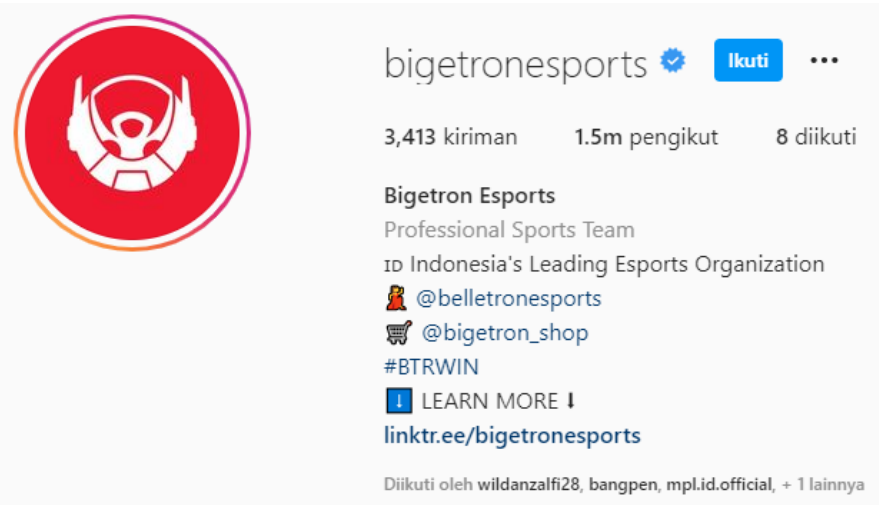

gambar 2.akun instagram bigetron esports

Sumber : https://www.instagram.com/bigetronesports/?hl=id (akses pada 22-10-2021)

\section{Alter Ego}

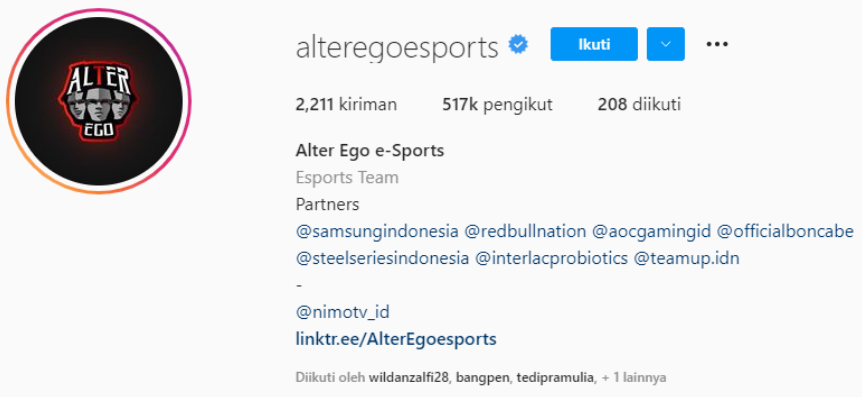

gambar 3. akun instagram alter ego esports

Sumber : https://www.instagram.com/alteregoesports/?hl=id (akses pada 22-10-2021)

\section{Evos}

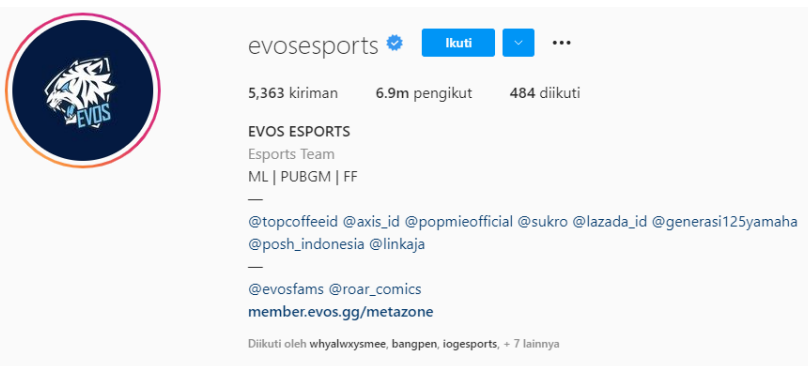

gambar 4. akun instagram evos esports

Sumber : $\underline{\text { https://www.instagram.com/evosesports/?hl=id (akses pada 22-10-2021) }}$

\section{Rex Regum Qeon}

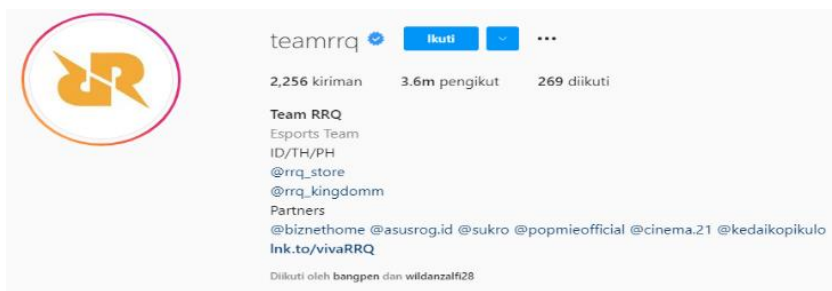

gambar 5. akun instagram rex regum qeon

Sumber : https://www.instagram.com/teamrrq/?hl=id (akses pada 22-10-2021) 
Dari kelima akun Instagram 5 tim terbaik mobile legend di Indonesia tahun 2020, peneliti menemukan nilai dari masing-masing variable yang ada untuk menghitung rasio Image Comments to Video Comments dari setiap akun. Pada akun Instagram terdapat 8 Variabel, diantaranya yaitu :

a. Variabel yang ditemukan pada halaman akun Instagram, yaitu :

1. Posts

2. Followers

3. Following

b. Variabel yang ditemukan pada halaman post Instagram, yaitu :

1. Image Likes

2. Image Comments

3. Video Views

4. Video Likes

5. Video Comments

Dari 8 variabel diatas, peneliti hanya fokus untuk menemukan hasil dari 2 variabel, yaitu :

1. Image Comments

2. Video Comments

Dari kedua variable tersebut kemudian dianalisa sehingga menemukan nilai rata-rata dari variable Image Comments dan variable Video Comments. Untuk menghitung nilai rata-rata dari variable image comments dan variable video comments yaitu dengan cara mengambil 10 postingan video dan 10 postingan gambar kemudian di hitung sehingga menemukan nilai ratarata dari masing-masing variable. Berikut merupakan tabel nilai rata-rata dari masing-masing tim terbaik mobile legend di Indonesia tahun 2020, yaitu :

Tabel 1 Analisa Nilai Rata-rata Nilai Variabel Image Comments dan Video Comments Akun Instagram Onic Esports

\begin{tabular}{|c|c|c|}
\hline No & Image Comments & Video Comments \\
\hline 1 & 31 & 20 \\
\hline 2 & 7 & 27 \\
\hline 3 & 24 & 16 \\
\hline 4 & 145 & 21 \\
\hline 5 & 70 & 16 \\
\hline 6 & 10 & 16 \\
\hline 7 & 106 & 45 \\
\hline 8 & 12 & 23 \\
\hline 9 & 17 & 458 \\
\hline 10 & 65 & 88 \\
\hline Total & 48,7 & 73 \\
\hline
\end{tabular}

Sumber : Pengelola Data Ecxel 
Tabel 2 Analisa Nilai Rata-rata Nilai Variabel Image Comments dan Video Comments Akun Instagram Bigetron Esport

\begin{tabular}{|c|c|c|}
\hline No & Image Comments & Video Comments \\
\hline 1 & 192 & 313 \\
\hline 2 & 236 & 87 \\
\hline 3 & 92 & 1341 \\
\hline 4 & 893 & 48 \\
\hline 5 & 638 & 538 \\
\hline 6 & 850 & 182 \\
\hline 7 & 376 & 310 \\
\hline 8 & 183 & 750 \\
\hline 9 & 59 & 228 \\
\hline 10 & 631 & 113 \\
\hline Total & 415 & 391 \\
\hline
\end{tabular}

Tabel 3 Analisa Nilai Rata-rata Nilai Variabel Image Comments dan Video Comments Akun Instagram Alter Ego Esports

\begin{tabular}{|c|c|c|}
\hline No & Image Comments & Video Comments \\
\hline 1 & 29 & 151 \\
\hline 2 & 36 & 175 \\
\hline 3 & 218 & 125 \\
\hline 4 & 31 & 98 \\
\hline 5 & 213 & 2777 \\
\hline 6 & 133 & 3103 \\
\hline 7 & 67 & 35 \\
\hline 8 & 78 & 153 \\
\hline 9 & 73843 & 150 \\
\hline 10 & 27 & 417 \\
\hline Total & 7467,5 & 718,4 \\
\hline
\end{tabular}

Sumber : Pengelola Data Ecxel

Tabel 4 Analisa Nilai Rata-rata Nilai Variabel Image Comments dan Video Comments Akun Instagram Evos Esports

\begin{tabular}{|c|c|c|}
\hline No & Image Comments & Video Comments \\
\hline 1 & 103 & 127 \\
\hline 2 & 52 & 45 \\
\hline 3 & 14 & 42 \\
\hline 4 & 299 & 193 \\
\hline 5 & 70 & 100 \\
\hline 6 & 61 & 72 \\
\hline 7 & 28 & 341 \\
\hline 8 & 206 & 168 \\
\hline 9 & 57 & 401 \\
\hline 10 & 71 & 91 \\
\hline Total & 96,1 & 158 \\
\hline
\end{tabular}


Sumber : Pengelola Data Ecxel

Tabel 5 Analisa Nilai Rata-rata Nilai Variabel Image Comments dan Video Comments Akun Instagram Rex Regum Qeon

\begin{tabular}{|c|c|c|}
\hline No & Image Comments & Video Comments \\
\hline 1 & 97 & 1178 \\
\hline 2 & 76 & 471 \\
\hline 3 & 161 & 898 \\
\hline 4 & 549 & 573 \\
\hline 5 & 47 & 233 \\
\hline 6 & 300 & 216 \\
\hline 7 & 125 & 97 \\
\hline 8 & 154 & 1284 \\
\hline 9 & 76 & 654 \\
\hline 10 & 436 & 92 \\
\hline Total & 202,1 & 569,6 \\
\hline
\end{tabular}

Setelah menghitung nilai rata-rata tersebut, maka akan menemukan hasil akhir nilai rata-rata dari variable Image Comments dan variable Video Comments.

Tabel 6 Nilai Variabel Pada Akun Instagram 5 Tim Mobile Legend Terbaik di Indonesia 2020

\begin{tabular}{|c|c|c|c|c|c|}
\hline Variable & Onic & Bigetron & $\begin{array}{c}\text { Alter } \\
\text { Ego }\end{array}$ & Evos & Rex Regum Qeon \\
\hline Image Comments & 48,7 & 415 & 7467,5 & 96,1 & 202,1 \\
\hline Video Comments & 73 & 391 & 718,4 & 158 & 569,6 \\
\hline
\end{tabular}

Pada akun Instagram terdapat 12 rasio yang relevan digunakan untuk mengukur kredibilitas pada masing-masing akun. Namun pada penelitian kali ini hanya berfokus untuk menghitung Image Comments to Video Comments. Untuk menghitung kredibilitas dari masing-masing akun Instagram setiap tim mobile legend bang bang, peneliti menghitung dengan cara : variabel 1 akan dibagi dengan variabel 2 , sehingga ditemukan hasil analisisa dari rasio tersebut.

Tabel 7 Hasil Perhitungan Rasio Akun Instagram

\begin{tabular}{|c|c|c|c|c|c|c|}
\hline Rasio & Onic & Bigetron & Alter Ego & Evos & $\begin{array}{c}\text { Rex Regum } \\
\text { Qeon }\end{array}$ & Karakteristik \\
\hline $\begin{array}{c}\text { Image } \\
\text { Comments } \\
\text { to Video } \\
\begin{array}{c}\text { Comments } \\
\text { Ratio }\end{array}\end{array}$ & 0,667123288 & 1,061381 & 10,39462695 & 0,608227848 & 0,354810393 & tinggi \\
\hline
\end{tabular}

Sumber : Pengelola Data Ecxel

Image Comments to Video Comments Ratio memiliki karakteristik yang tinggi, artinya semakin tinggi nilai yang dihasilkan maka semakin baik kredibilitas dari performa akun tersebut. Untuk memberikan peringkat pada masing-masing tim mobile legend bang bang terbaik di indonesia, peneliti memberikan angka 5 kepada vendor yang mendapatkan nilai tertinggi dan angka 1 untuk tim mobile legend terbaik di indonesia yang mendapatkan nilai 
terendah. Berikut merupakan tabel urutan nilai yang dihasilkan oleh masing-masing klub sepakbola terpopuler di indonesia.

Tabel 8 Nilai Rasio Akun Instagram Tim Mobile Legend Terbaik di Indonesia

\begin{tabular}{|c|c|c|c|c|}
\hline Onic & Bigetron & $\begin{array}{c}\text { Alter } \\
\text { Ego }\end{array}$ & Evos & Rex Regum Qeon \\
\hline 3 & 4 & 5 & 2 & 1 \\
\hline
\end{tabular}

Sumber : Pengelola Data Ecxel

Dari tabel nilai rasio 5 akun instagram tim mobile legend bang bang terbaik di Indonesia pada tahun 2020 dapat disimpulkan bahwa Akun Instagram Alter Ego mendapatkan nilai tertinggi untuk rasio Image Comments to Video Comments. Sedangkan akun Instagram Rex Regum Qeon mendapatkan nilai terendah untuk rasio ini. Jadi, pada penelitian ini akun Alter Ego memiliki kredibilitas performa yang lebih baik dibandingkan dengan akun Tim Mobile Legend yang lainnya. 


\section{DAFTAR PUSTAKA}

5 Tim Mobile Legends Terbaik di Indonesia Musim Ini - Terminal Mojok. (n.d.). Retrieved October 26, 2021, from https://mojok.co/terminal/5-tim-mobile-legends-terbaik-di-indonesia-musim-ini/

Febrina, A. (2019). Motif Orangtua Mengunggah Foto Anak di Instagram (Studi Fenomenologi Terhadap Orangtua di Jabodetabek). Jurnal Abdi Ilmu, 12(1), 55-65. http://jurnal.pancabudi.ac.id/index.php/abdiilmu/article/view/529

Hendika Permana, I. P. (2021). Analisis Rasio Pada Akun Youtube Untuk Penelitian Kualitatif Menggunakan Metode Ekploratif. Jurnal Ilmiah Media Sisfo, 15(1), 40. https://doi.org/10.33998/mediasisfo.2021.15.1.970

Inilah Negara Pengguna Instagram Terbanyak, Indonesia Urutan Berapa? / Databoks. (n.d.). Retrieved October 26, 2021, from https://databoks.katadata.co.id/datapublish/2021/08/03/inilah-negarapengguna-instagram-terbanyak-indonesia-urutan-berapa

Moreau, E. (2018). What Is Instagram, Anyway? Lifewire, 1-9. https://conference.bcoe.org/cabinet/file/df703dbd-0a56-4b5f-8909$8 \mathrm{~d} 850180 a 7 d d /$ What_is_Instagram.pdf

Mudjiyanto, B. (2018). Tipe Penelitian Eksploratif Komunikasi. Jurnal Studi Komunikasi Dan Media, 22(1), 65. https://doi.org/10.31445/jskm.2018.220105

Nur Arifah, F. (2015). Analisis Sosial Media Sebagai Strategi Marketing Dalam Bisnis Online. Jurnal TRANSFORMASI, 11(2), 143-149.

Restusari, F. N., \& Farida, N. (2019). Instagram Sebagai Alat Personal Branding Dalam Membentuk Citra Diri (Studi Pada Akun Bara Pattiradjawane). Mediakom : Jurnal Ilmu Komunikasi, 3(2), 176186. https://doi.org/10.35760/mkm.2019.v3i2.2340 